\title{
Preserved motor asymmetry in late adulthood: Is measuring chronological age enough?
}

$$
\text { Sydney Y. Schaefer, } \mathrm{PhD}^{\mathrm{a}, \mathrm{b}, \mathrm{c}}
$$

${ }^{a}$ Emma Eccles Jones College of Education and Human Services, Utah State University;

${ }^{\mathrm{b}}$ Department of Physical Therapy, University of Utah; ${ }^{\mathrm{c}}$ The Center on Aging, University of Utah

Corresponding author: $\quad$ Sydney Y. Schaefer, $\mathrm{PhD}$

${ }^{a}$ Utah State University

7000 Old Main Hill

Logan, UT 84322 USA

Phone: (435) 797-8441

Fax: (435) 797-3759

Email: sydney.schaefer@usu.edu

${ }^{b}$ Department of Physical Therapy

University of Utah

520 Wakara Way

Salt Lake City, UT 84108

${ }^{c}$ The Center on Aging

University of Utah

30 North 1900 East, AB193 SOM

Salt Lake City, UT 84132

Number of words: 4,484

Number of figures: 4

Number of tables: 1 


\section{ABSTRACT}

When comparing motor performance of the dominant and nondominant hands, older adults tend to be less asymmetric compared to young adults. This has suggested decreased motor lateralization and functional compensation within the aging brain. The current study further addressed this question by testing whether motor asymmetry was reduced in a sample of 44 healthy right-handed adults ages 65-89. We hypothesized that the older the age, the less the motor asymmetry, and that 'old old' participants (age 80+) would have less motor asymmetry than 'young old' participants (age 65-79). Using two naturalistic tasks that selectively biased the dominant or nondominant hands, we compared asymmetries in performance (measured as a ratio) across chronological age. Results showed preserved motor asymmetry across ages in both tasks, with no difference in asymmetry ratios in the 'old old' compared to the 'young old.' In the context of previous work, our findings suggest that the aging brain may also be characterized by additional measures besides chronological age.

Key words: motor lateralization; asymmetry; aging; upper extremity; naturalistic task Abbreviations: Dominant $=\mathrm{D} ;$ Nondominant $=$ ND 
1. Hemispheric specialization is considered a key feature of neural organization (Toga and Thompson, 2003). One outcome of such organization is the lateralization of certain behaviors, including upper extremity movement. A growing amount of evidence in animals and humans has strongly suggested that the control system for upper extremity movement is lateralized across the two cerebral hemispheres (Chatagny et al., 2013; Frayer et al., 2010; Meguerditchian et al., 2013; Sainburg, 2014; Uomini, 2009; Zhao et al., 2012). More specifically, the dominant hemisphere (i.e. the left hemisphere of right handers) appears to be specialized for controlling movements through predictive mechanisms that effectively coordinate multiple limb segments, which are optimal when movement conditions are consistent and stable (Bagesteiro and Sainburg, 2002; Coelho et al., 2013; Sainburg and Kalakanis, 2000). Beyond and in contrast to this, the nondominant hemisphere (i.e. the right hemisphere of right handers) may be specialized for maintaining limb stability and resisting unexpected perturbations from the environment (Bagesteiro and Sainburg, 2003; Mutha et al., 2012). Further research suggests that with this nondominant hemispheric advantage, the left hand may also be better at static object manipulation compared to the right hand (Ferrand and Jaric, 2006; Judge and Stirling, 2003) when limb choice/preference is constrained, perhaps through better limb stability at the endeffector (hand).

In concert with hemispheric differences in motor planning and execution, the lateralization of other sensorimotor functions may also contribute to manual asymmetries (for review see Goble and Brown, 2008; Starkes et al., 2002). For example, the left and right hemispheres appear to utilize (Flowers 1975; Roy and Elliott, 1986; Todor and Doane, 1978), process and weight (Adamo and Martin, 2009; Martin and Adamo, 2011) movement-related visual and somatosensory feedback differently, and may even allocate spatial attention 
differently (Hodges et al., 2007). Although these sensorimotor asymmetries are strongest in right-handed individuals, the respective roles of the dominant and nondominant hemispheres during voluntary upper extremity movement are relatively maintained in left-handed adults as well (Goble et al., 2009; Legon et al., 2010; Przybyla et al., 2012; Wang and Sainburg, 2006). Thus, depending on a given task and its requirements, the dominant and nondominant hands may perform differently, with one hand being better at the task than the other.

Dominant and nondominant hand performance may, however, become more symmetric with age. Numerous behavioral studies have documented age-related reductions in motor asymmetry when moving unimanually (Przybyla et al. 2011; Raw et al. 2012), transferring learned information between the limbs (Wang et al., 2011), and even imagining movements (Paizis et al., 2014), such that the intermanual difference is smaller than in young adults. One explanation is that reductions in age-related asymmetries may reflect functional compensation in older adults through increased ipsilateral hemispheric activation. This hypothesis has emerged from research in other lateralized non-motor systems, such as working memory encoding and retrieval (Cabeza, 2002; Cabeza et al., 2002; Dolcos et al., 2002; Reuter-Lorenz et al., 1999), yet may not hold as true for voluntary motor control given the often co-morbid aspects of aging like muscle and bone loss, cardiopulmonary dysfunction, and response slowing (Spirduso et al., 2005). Nevertheless, models of compensatory cortical recruitment may be applicable when considering less asymmetry in motor performance for older adults.

The age 'effect' on motor asymmetry has typically been modeled dichotomously, however, where the difference between dominant and nondominant hand performance is compared between young and older adults. To more clearly understand whether reductions in motor asymmetry are in fact age-related, however, one could also investigate this question by 
modeling age as a continuous variable and within later adulthood. Thus, the purpose of this study was to test whether motor asymmetry was further reduced with advanced chronological age. Using two different motor tasks that theoretically biased either the dominant or nondominant hands for coordination or manipulation respectively, we hypothesized that the older the age, the less the motor asymmetry in a sample of healthy adults ages 65 and over. We also hypothesized the 'old old' (age 80+) would have less motor asymmetry than the 'young old' (age 65-79).

\section{EXPERIMENTAL PROCEDURES}

\subsection{Participants}

Forty-four right-handed adults age 65 years or older (mean \pm SD: $75.4 \pm 6.6$ years) from the local community $(n=43)$ or senior assisted-living apartments $(n=1)$ participated in this study. Recruitment was based on individuals who contacted the laboratory with interest in participating as a result of approved postings throughout Cache County. Exclusion criteria included 1) one or more self-reported neurological conditions (e.g., Parkinson's disease, Huntington's disease, Alzheimer's disease, stroke, or transient ischemic attack); 2) acute or chronic musculoskeletal conditions that could affect motor function; and 3) left- or mixed-handedness (see below). All aspects of this study were conducted in accordance with the Declaration of Helsinki, and all procedures were carried out with the adequate understanding and prior written consent of the participants as approved by the University's Institutional Review Board.

Participants' cognitive and sensorimotor functions were characterized prior to completing the motor task. Global cognitive status was measured with the Montreal Cognitive Assessment (MoCA) (Nasreddine et al., 2005), which is a reliable, easily administered, and brief cognitive screening test $(\max$ score $=30$; "normal" score cutoff $\geq 26$ ). General disability was tested for 
with the Index of Independence in Activities of Daily Living (Katz et al., 1970) in order to assess functional ability in daily life. This index is a paper-and-pencil test in which participants selfreport their level of assistance needed to complete each of the six activities of daily living functions: feeding, continence, transferring, going to toilet, dressing, and bathing. Reports of "no assistance needed" were scored as 1; the maximum (worst) score was 18, which indicated "dependent in all six functions." No additional measure of physical fitness or activity was collected. Tactile sensation was measured with Semmes Weinstein monofilaments (TouchTest $^{\mathrm{TM}}$, North Coast Medical, Inc., Gilroy, CA) at the distal end of the dominant and nondominant index fingers. Maximal grip strength of the dominant and nondominant hand was tested via hand dynamometry (Jamar, Sammons-Preston-Rolyan, Bolingbrook, IL) and measured as the average of three consecutive measurements for each hand (Schmidt and Toews, 1970). Hand dominance was determined using a modified Edinburgh Handedness Questionnaire (Oldfield, 1971). Only participants with a laterality quotient of $\geq 80 \%$ ("strongly right-handed") were included in this study, but no further data regarding their occupation or potential for longterm hand training over their lifespan was collected. All participant characteristics are summarized in Table 1.

\subsection{Experimental tasks}

The two motor tasks used in this study were a simulated dressing task and a simulated feeding task. Additional justification and images of these naturalistic tasks have been published previously (Schaefer and Lang, 2012; Schaefer et al., 2013; Schaefer et al., 2014). We operationally defined 'naturalistic' in this study as requiring purposeful, multi-step actions 
(Giovannetti et al., 2002; Hartmann et al., 2005; Schwartz et al., 1998) rather than involving only one movement component (e.g. only reaching).

The simulated dressing task in this study required participants to manipulate buttons and fasten them sequentially with one hand on a button board (Backman et al., 1992) (Fig. 1A). At the start of each trial, participants began buttoning the top of ten buttons $(2.5 \mathrm{~cm}$ diameter $)$ that were sewn $5.3 \mathrm{~cm}$ apart vertically to a piece of heavyweight linen fabric, $3.0 \mathrm{~cm}$ from the edge. The buttonholes were $3.7 \mathrm{~cm}$ in length. Both pieces of the fabric were double-layered (2-ply) and were secured to a wooden board $(61 \mathrm{~cm} \mathrm{x} 34 \mathrm{~cm})$, with the placket centered at the participants' midline, $15 \mathrm{~cm}$ in front of them. The button-side of the fabric was folded onto the board, while the button hole-side of the fabric was unfolded lateral to midline onto the table prior to each trial. Fabric weight $\left(65.6 \mathrm{~g} / \mathrm{m}^{2}\right)$ and thread count $(15$ per $\mathrm{cm})$ were measured according to ASTM Test Methods D3776-96 and D3775-98, respectively (ASTM, 2001a, b). Buttons were fastened through horizontal button holes in a lateral-over-medial order, relative to the participant. Participants were instructed to fasten the 10 buttons consecutively (from top to bottom) as quickly as possible with either their left (nondominant) or right (dominant) hand, equaling one trial. The experimenter monitored the ongoing trials to ensure that each button was completely through the button hole; if a button was not completely through before the participant moved on to the next button, the participant was informed to return to the incomplete repetition and do so as time continued to elapse. Thus, the measure of performance was the time taken to complete the 10 buttons (i.e. "trial time"), with faster times indicating better performance. Given this task's requirement of manipulating a static object (Ebersbach et al., 1995; Soliveri et al., 1992), we expected that the nondominant hand would have faster trial times than the dominant hand. 
The simulated feeding task requires repetitive multijoint coordination and has been adapted from the simulated feeding subtest of a clinical assessment (Jebsen et al., 1969) that objectively assesses hand function for activities of daily living. This task required participants to spoon beans (kidney, raw) at a time from a center proximal "start" cup to three distal "target" cups as fast as possible (Fig. 1B). The cups $(9.5 \mathrm{~cm}$ in diameter) were secured to a board $(60.5 \mathrm{~cm}$ $\mathrm{x} 40.0 \mathrm{~cm}$ ), with three target cups secured radially at $45^{\circ}, 90^{\circ}$, and $135^{\circ}$ around the start cup at a distance of $16 \mathrm{~cm}$. The start cup was oriented along the participant's midline and $15 \mathrm{~cm}$ in front of the seated participant. One repetition of the motor task consisted of spooning two beans at once from the start cup to a target cup with the nondominant hand (Cherry et al., 2014; Schaefer and Lang, 2012; Schaefer et al., 2014), with one trial equaling 15 repetitions. During each trial, participants were instructed to move as quickly yet as accurately as possible, first to the left target cup, next to the center target cup, and then to the right cup. They repeated this sequence five times to complete the trial. Any unsuccessful attempts (e.g. only one bean was placed into a target cup per repetition) were not counted as time continued to elapse. Each trial began when the participants picked up the spoon (plastic, $5.21 \mathrm{~g}$ ) and ended when they returned the spoon to its start location ( $5 \mathrm{~cm}$ lateral to the start cup). The measure of performance was the time taken to complete 15 successful repetitions (i.e. "trial time"), with faster times indicating better performance. Given this task's requirement for multijoint coordination and limb reversal (Sainburg et al., 1995), we expected that the dominant hand would have faster trial times than the nondominant hand.

In both tasks, all trials were timed to the nearest $100^{\text {th }}$ of a second via stopwatch. In contrast to some experimental or therapeutic approaches (Winstein, 1991), participants were given no explicit feedback (i.e. knowledge of performance or results) after each trial, and were 
not encouraged to adopt any specified pattern of upper extremity kinematics during training. Instead, participants used self-selected movement strategies to complete each task. During data collection, all participants completed individual trials of each task with their dominant and nondominant hands. We did not assume that the dressing task required only manipulation and no coordination, nor that the feeding task required only coordination and not manipulation; instead, we posited that the tasks had either more manipulation or coordination requirements relative to each other in order to minimize trial time. Although participants were instructed to move quickly, trial time in both tasks reflected not only the speed of performance but also some level of accuracy as well. For example, if the participant missed a button or did not fully fasten it through the button hole, time continued to elapse as he or she returned to the incomplete repetition to do so. Time also continued to elapse if participants dropped beans during transport, missed a target, or had any difficulty loading two beans onto the spoon from the home cup (i.e. rooting around). Because these data were collected in a baseline session for a larger training study (Schaefer et al., 2014) that involved testing the nondominant hand then the dominant hand, only task order (dressing vs. feeding) was randomized in this study. Our data (see Section 3.1.) did not, however, suggest any intermanual transfer learning effects per se.

\subsection{Data and statistical analyses}

To quantify the degree of motor asymmetry, we computed an asymmetry ratio for each participant for each task by dividing dominant hand performance (trial time) by nondominant hand performance (D/ND). Thus, an asymmetry ratio of 1 would indicate equivalent performance for the dominant and nondominant hands, whereas values $>1$ would indicate that the nondominant hand was faster (i.e. better) than the dominant hand when completing the tasks. 
Likewise, ratio values $<1$ would indicate that the dominant hand was faster (i.e. better) than the nondominant hand.

JMP 10.0 (SAS Institute Inc., Cary, NC) was used for all statistical analyses $(\alpha=.05)$. A $2 \times 2$ repeated measures analysis of variance (ANOVA) first compared dominant and nondominant hand performance (D vs. ND) between tasks (dressing vs. feeding), both as withinsubject factors, to test whether the selected tasks did in fact a) yield manual asymmetries in our sample and b) correctly bias either the dominant hand for coordination (i.e. simulated feeding) or the nondominant hand for manipulation (i.e. simulated dressing) as predicted. Posthoc analyses were conducted when warranted using the Tukey-Kramer Honestly Significant Difference (HSD) test. The remaining analyses described below were conducted within each task; no further between-task comparisons were made since we had no a priori hypotheses about which task would yield more motor asymmetry or more age-related declines in asymmetry.

To test our first hypothesis that the older the age, the less the motor asymmetry, we determined the linear relationship between asymmetry ratio and age using least squares regression. To test our second hypothesis that the 'old old' would have less motor asymmetry than the 'young old', we first assigned participants to either category based on their age (80 years or older, $n=16$ vs. $65-79$ years, $n=27$ ) (Forman et al., 1992). We then compared asymmetry ratios between age groups using an independent $T$-test. In comparing asymmetry ratios between age categories, assumptions of equal variances and normality were tested with Brown-Forsythe and Shapiro-Wilk tests, respectively. In cases of non-normality, Mann-Whitney tests were used rather than $T$-tests.

\section{RESULTS}




\subsection{Different tasks yielded different hand advantages}

Figure 2 shows how each task selectively biased either the dominant or nondominant hand, as expected. Our ANOVA revealed a significant interaction effect between hand (D vs. ND) and task (dressing vs. feeding) on trial time $\left(\mathrm{F}_{1,43}=41.3, p<.0001\right)$. Posthoc analyses determined that the nondominant hand was faster (i.e. better) than the dominant hand on the dressing task $(p<.05)$, whereas the dominant hand was faster (i.e. better) than the nondominant hand on the feeding task $(p<.0001)$. Thus, these tasks not only yielded manual asymmetries in our sample, but also showed predictable manual advantages that were likely based on differing task requirements (manipulation vs. coordination).

\subsection{Relationship between motor asymmetry and advancing age?}

As described in 2.3, we computed an asymmetry ratio that expressed dominant hand performance relative to nondominant hand performance (D/ND). If less motor asymmetry was associated with older age in our sample, we would expect to see these values converge to 1 as participant age increased, which would indicate more symmetry between the hands on a given task. Results shown in Figure 3 do not, however, support this hypothesis. Least squares regression revealed no significant linear relationship between asymmetry ratio and age for either the dressing task $(p=.75)$ or the feeding task $(p=.75)$ (Fig. 4$)$. In the both tasks, less than $1 \%$ of the variance in asymmetry ratio was explained by participants' age ( $r^{2}=.0024$ in both cases).

We further compared asymmetry ratios between age groups ('young old', $n=28$ vs. 'old old', $n=16$ ) for each task. Although ratios were $>1$ for the dressing task and $<1$ for the feeding task (see Fig. 3), there was no significant difference between asymmetry ratios in the 'young old' and 'old old' groups for the dressing task (Mann-Whitney $U=.79 ; p=.42$ two-tailed) or the 
feeding task (independent T-test; $p=.96$ ) (Fig. 4). Variances were considered equal between age groups for both tasks (all Brown-Forsythe statistics: $p>.19$ ). Although we did not control for cognitive impairment in this convenience sample of participants, two-tailed Fisher's exact tests further indicated no significant difference in proportions of gender (male vs. female; $p=.32$ ) or mild cognitive impairment (MoCA score $<26$ vs. $\geq 26 ; p=.13$ ) between the 'young old' vs. 'old old' age groups. With comparable samples of males vs. females and those with vs. without mild cognitive impairment (based on MoCA score only) in both age groups, we also tested whether our asymmetry ratios were related to gender or cognitive status. Independent T-tests indicated that asymmetry ratios were not significantly different based on gender (dressing; $p=.09$ and feeding; $p=.57$ ) nor on cognitive status (dressing; $p=.21$ and feeding; $p=.67$ ).

\subsection{Relationship between overall motor performance and advancing age}

Although our data did not show a significant effect of age on motor asymmetry, we did in fact observe an effect of age and age-related factors on overall motor performance. Trial times for both the dominant and nondominant hands were 1$)$ positively correlated with age $\left(\mathrm{r}^{2}\right.$ values from .18 to .30; all $p<.01)$ and 2$)$ negatively correlated with MoCA score $\left(\mathrm{r}^{2}\right.$ values from .10 to .15 ; all $p<.05)$ in both tasks, in spite of no correlation between these factors and motor asymmetry itself. In other words, the older the participants or the lower the MoCA scores were, the longer the trial times were, regardless of whether they were using their dominant or nondominant hand. The difference in trial times between the hands, however, was not dependent on the participants' ages (see Figs. 3 and 4). Thus, this measure of motor asymmetry may reflect something distinct from general performance and/or factors related chronological age. 


\section{DISCUSSION}

The purpose of this study was to test whether motor asymmetry was further reduced with age in late adulthood. Using two different functional motor tasks, we hypothesized that the older the chronological age, the less the motor asymmetry would be in a convenience sample of healthy right-handed adults age 65 and older. We found that 1) the difference between dominant and nondominant hand performance on either motor task did not decrease with advancing age, and 2) the 'old old' participants in our sample (ages 80-89) did not have less asymmetry in either task compared to the 'young old' (ages 65-79). These findings add further insight into motor lateralization and how to better quantify aging within the central nervous system, as discussed below.

First, compelling evidence from patients with lateralized cortical lesions in sensorimotor regions due to stroke (Freitas et al., 2011; Haaland et al., 1987; Haaland and Harrington, 1994, 1996; Harrington and Haaland, 1991, 1992; Schaefer et al., 2007, 2009a, b; Schaefer et al., 2012; Stewart et al., 2014; Tretriluxana et al., 2009; Winstein and Pohl, 1995) has demonstrated the specialized roles of the left and right hemispheres for upper extremity movement. These studies predict that different motor tasks would yield different manual advantages when performed with only one hand, yet the tasks' requirements would determine which hand would be better. While these predictions have been substantiated by data from young healthy adults (see Section 1 . Introduction), the current study now provides further evidence for the persistence of manual advantages in older adults as predicted by some models of lateralization (Sainburg, 2014). Furthermore, because this extensive work in younger populations has been able to map specific motor control mechanisms onto the left and right hemispheres, we were now able to test our tasks' proof-of-concept in older adults by demonstrating a double dissociation of hand and task. 
Thus, our two naturalistic motor tasks did in fact bias different aspects of movement control. We acknowledge that the preservation of motor asymmetry across ages in our sample may be taskspecific (Teixeira, 2008), but the relative advantages of the nondominant and dominant hands for the dressing and feeding tasks (respectively) suggest that the dressing and feeding tasks favor separate control mechanisms remain lateralized in older adults.

Second, although we did not observe any differences in performance asymmetry across ages, there may have been differences in hemispheric activation patterns across ages. Neuroimaging data from within and outside of sensorimotor networks have demonstrated an increase in ipsilateral hemispheric activity with increasing age (Dolcos et al., 2002; Naccarato et al., 2006; Talelli et al., 2008; Ward, 2006). The primary interpretation of these previous findings is that the two hemispheres cooperate during the performance of a given cognitive or motor task, particularly when it is more complex or difficult (Banich and Belger, 1990; Weissman and Banich, 2000), in order to compensate for age-related neural decline. Dolcos et al. (2002) note that a 'difficult' task for older adults may not be difficult for young adults; thus, bihemispheric processing may be necessary for older adults to maintain task performance whereas unilateral processing may be sufficient for young adults (Reuter-Lorenz et al., 1999). Thus, in this study, it is plausible that the simulated dressing and/or simulated feeding tasks were more challenging or complex for the 'old old' participants compared to the 'young old', and they may have recruited additional ipsilateral neural resources to compensate. We did in fact observe an aging effect in overall motor performance (but not asymmetry), such that trial time itself was correlated with chronological age and cognitive status for both the dominant and nondominant hands in both tasks, consistent with other data from this sample (Schaefer et al., 2014). This also adds to previous findings by showing that cognitive status in older adults can affect movement speed 
during functional upper extremity movements in addition to lower extremity movements (e.g. Aggarwal et al., 2006; Wilson et al., 2003), further strengthening the notion that poorer sensorimotor performance may coexist with or uncover mild cognitive impairment (Reppermund et al., 2013). Given the relationship between task difficulty and movement time (Fitts, 1954), we could perhaps infer from their trial times that these tasks were more difficult for the older participants or those with cognitive impairments in our sample (see Michimata et al., 2008), but we cannot at this time determine the symmetry of either group's hemispheric activation patterns (or changes in such) when performing either motor task based on trial time alone. Future work in functional neuroimaging is necessary to determine if the lack of age-related reductions in performance asymmetry reflect adequate neural compensation by the ipsilateral hemisphere, or some other preserved organization of motor control with aging. Nevertheless, our results at this time are inconsistent with some previous work (see Section 1. Introduction) yet actually support other reports of preserved motor asymmetry in older adults (Chua et al., 1995; Francis and Spirduso, 2000; Michimata et al., 2008; Poston et al., 2008). This may be related to how simple vs. complex the tasks are for assaying motor asymmetry, whether by experimental design (e.g. Francis and Spirduso, 2000) or because of lack of novelty (e.g. Poston et al., 2008).

Third, participants' ages were defined in this study according to their chronological age. This may further explain the equivocality in whether aging affects motor asymmetry, above and beyond any aspects of the tasks themselves. Although chronological age is commonly used in research to quantify one's age, it is not the only way to express age experimentally. Given that aging is a multi-factorial process (Spirduso et al., 2005), other metrics of age that could be used in research include psychological age (e.g. Jeste et al., 2013), biological age (e.g. DeCarlo et al., 2014), and 'functional age' (e.g. Fried et al., 2001). These ages tend to co-vary with 
chronological age, but only to a certain extent. For example, one specific biomarker of functional age is grip strength, which, when normalized for age, gender, and body mass index (BMI), can be a proxy for one's level of frailty (Ahmed et al., 2007; Cigolle et al., 2009). Thus, when comparing two gender- and BMI-matched individuals who have the same chronological age (e.g. 75 years old) but different grip strength, the individual with the lower grip strength would be considered functionally 'older' based on evidence of frailty. Because only nine of the 44 participants in this study had grip strengths below their age- and gender-matched norms (based on Bohannon et al., 2006), our sample likely spanned a wide chronological age range but a narrow 'functional' age range. This interpretation is further supported by the low median score on the Index of Independence in ADL assessment, which indicated that this sample was free of disability (Katz et al., 1970) and highly independent in their activities of daily living. Thus, participants in this study may have been of similar age functionally, despite being different ages chronologically.

This similar 'functional age' may have masked some changes in motor asymmetry that have been documented in other previous comparisons between young vs. older adults who, in those cases, are obviously different both in terms of chronological and functional ages. We nevertheless acknowledge our limitation of not directly determining differences in asymmetry ratios between young vs. older adults in this study, but note that one advantage of this study is the convenience sample of older right-handed adults that captured a wide range of chronological age. This wide age range appeared, however, to hold alternative proxies of age (e.g. ADL independence or frailty) relatively constant in spite of smaller samples in the upper range of the 'old old' group. With this in mind, motor asymmetry may still be reduced with advancing age (as supported by previous studies), but this decline may be more related to advancing 'functional 
age' rather than chronological age. Future studies in older adults could test this hypothesis by measuring asymmetries (motor or otherwise) in participants with the same chronological age but varying degrees of ADL dependence or frailty, and plotting asymmetry as a function of these variables rather than chronological age itself. This future approach would in fact be in line with the call by others (see Talelli et al., 2008) for identifying other biomarkers and neurophysiological measures that better characterize neural decline with advancing age (Franke and Gaser, 2012).

\section{CONCLUSION}

This study provides dominant and nondominant upper extremity motor performance data on two naturalistic tasks in a convenience sample of healthy older right-handed adults up to 89 years of age. The two tasks used in this study appeared to bias different control mechanisms, resulting in different performance advantages for the two hands, but did not show any reduced asymmetries with advancing chronological age. Knowing the 'normal' asymmetries associated with these tasks in older adults now allows us to more clearly understand and interpret other abnormal asymmetries that may be present in Alzheimer's Disease (Derflinger et al., 2011; Postiglione et al., 1993), Parkinson's Disease (Karadi et al., 2015; Riederer and Sian-Hulsmann, 2012), and other age-related neurological disorders. Other measures besides purely chronological age, however, may provide a clearer picture of the aging brain and functional lateralization.

\section{ACKNOWLEDGEMENTS}

The author would like to acknowledge those who helped with data collection (J. Gardner, B. Lindauer, A. Squire, and A. Waite). This work was supported in part by the Utah State 
University Office of Research and Graduate Studies (RC \#28037) and the Marriner S. Eccles Foundation. Neither funding source influenced the study design; the collection, analysis and interpretation of data; the writing of the report; nor the decision to submit the article for publication. 


\section{TABLES}

Table 1. Group characteristics.

\begin{tabular}{|c|c|c|c|c|c|c|c|c|c|}
\hline $\begin{array}{c}\text { Age (yrs) } \\
\text { median }\end{array}$ & Sex & $\begin{array}{l}\mathbf{M o C A}^{\mathbf{a}} \\
\text { median }\end{array}$ & $\begin{array}{l}\mathbf{A D L s}^{\mathbf{b}} \\
\text { median }\end{array}$ & Tac & le sens & $\operatorname{ation}^{\mathrm{c}}$ & Maxime & $\begin{array}{l}\text { grip stre } \\
\text { mean }(S D\end{array}$ & gth $(\mathrm{kg})^{\mathrm{d}}$ \\
\hline \multirow[b]{2}{*}{$\begin{array}{c}75 \\
(65-89)\end{array}$} & \multirow[b]{2}{*}{$\begin{array}{l}15 \mathrm{M} \\
29 \mathrm{~F}\end{array}$} & \multirow[b]{2}{*}{$\begin{array}{c}25 \\
(17-30)\end{array}$} & \multirow[b]{2}{*}{$\begin{array}{c}6 \\
(6-10)\end{array}$} & & $\mathrm{D}$ & ND & \multirow[b]{2}{*}{ M } & $\mathrm{D}$ & ND \\
\hline & & & & $\begin{array}{l}2.83 \\
3.61 \\
4.31 \\
6.61\end{array}$ & $\begin{array}{l}n=18 \\
n=22 \\
n=4 \\
n=0\end{array}$ & $\begin{array}{l}n=25 \\
n=15 \\
n=3 \\
n=1\end{array}$ & & $33.8(7.1)$ & $34.3(6.5)$ \\
\hline
\end{tabular}

All participants were right-handed. $\mathrm{D}=$ dominant (right) hand; $\mathrm{ND}=$ nondominant (left) hand. $\mathrm{M}=\mathrm{male} ; \mathrm{F}=$ female.

${ }^{\mathrm{a}}$ Maximum MoCA score $=30$. Scores above 26 are considered normal.

${ }^{\mathrm{b}}$ Total score as computed from Index of Activities of Daily Living (ADLs). Minimum (best) score reported as $6=$ "independent in feeding, continence, transferring, going to toilet, dressing, and bathing"; maximum (worst) score is $18=$ "Dependent in all six functions."

${ }^{\mathrm{c}}$ Sensation of the index fingertip, palmar surface, expressed as lowest (finest) detectable Semmes-Weinstein monofilament thickness. 2.83, 3.61, 4.31, and 6.61 are manufacturer-assigned numbers, with higher values indicating stiffer monofilaments, according to formula: nominal value $=\log _{10}$ [bending force (in milligrams) $\left.\mathrm{x} 10\right]$. $n=$ number of participants.

${ }^{\mathrm{d}}$ Measured via dynamometer; average of three consecutive measurements, in randomized order. 


\section{FIGURE CAPTIONS}

Figure 1. Top views of the simulated A) dressing and B) feeding tasks. Note: Setup shown is for testing the left hand. Items are not necessarily drawn to scale.

Figure 2. Comparison of dominant and nondominant hand performance. Mean \pm SE trial times for the dominant (D) and nondominant (ND) hands on the dressing and feeding tasks $\left({ }^{* * *} p<.0001 ; * p<.05\right)$. Lower trial times indicate better performance.

Figure 3. Relationship between asymmetry ratio and age. Asymmetry ratio is plotted as a function of participant age for both the dressing $(O)$ and feeding $(\bullet)$ tasks. Ratio values $>1$ indicate that the participant's nondominant hand was faster on that task; $<1$ indicates that the dominant hand was faster. Values closer to 1 indicate more symmetry. Best-fit lines are shown for the dressing (dashed) and feeding (solid) tasks, as determined by least squares regression.

Figure 4. Effect of age group on asymmetry ratio. Mean \pm SE asymmetry ratios for the 'young old' (ages 65-79) and 'old old' (ages 80+) on the dressing and feeding tasks (n.s. $=$ not significant). Values closer to 1 (dotted line) indicate more symmetry. 


\section{REFERENCES}

Adamo DE, Martin BJ (2009), Position sense asymmetry. Exp Brain Res 192(1):87-95.

Aggarwal NT, Wilson RS, Beck TL, Bienias JL, Bennett DA (2006), Motor dysfunction in mild cognitive impairment and the risk of incident Alzheimer disease. Arch Neurol 63:17631769.

Ahmed N, Mandel R, Fain MJ (2007), Frailty: an emerging geriatric syndrome. Am J Med 120:748-753.

ASTM (2001a), D3776-96 Standard Test Methods for Mass Per Unit Area (Weight) of Fabric. ASTM International, West Conshohocken, PA.

ASTM (2001b), D3775-98 Standard Test Method for Fabric Count of Woven Fabric. ASTM, West Conshohocken, PA.

Backman C, Cork S, Gibson D, Parsons J (1992), Assessment of hand function: The relationship between pegboard dexterity and applied dexterity. Can J Occup Ther 59(4):208-213.

Bagesteiro LB, Sainburg RL (2002), Handedness: dominant arm advantages in control of limb dynamics. J Neurophysiol 88:2408-2421.

Bagesteiro LB, Sainburg RL (2003), Nondominant arm advantages in load compensation during rapid elbow joint movements. J Neurophysiol 90:1503-1513.

Banich MT, Belger A (1990), Interhemispheric interaction: how do the hemispheres divide and conquer a task? Cortex 26:77-94.

Bohannon RW, Peolsson A, Massy-Westropp N, Desrosiers J, Bear-Lehman J (2006), Reference values for adult grip strength measured with a Jamar dynamometer: a descriptive metaanalysis. Physiotherapy 92:11-15. 
Boyle JB, Shea CH (2011), Wrist and arm movements of varying difficulties. Acta Psychol (Amst). 137(3):382-396.

Cabeza R (2002), Hemispheric asymmetry reduction in older adults: the HAROLD model. Psychol Aging 17:85-100.

Cabeza R, Anderson ND, Locantore JK, McIntosh AR (2002), Aging gracefully: compensatory brain activity in high-performing older adults. Neuroimage 17:1394-1402.

Chatagny P, Badoud S, Kaeser M, Gindrat AD, Savidan J, Fregosi M, Moret V, Roulin C, Schmidlin E, Rouiller EM (2013), Distinction between hand dominance and hand preference in primates: a behavioral investigation of manual dexterity in nonhuman primates (macaques) and human subjects. Brain Behav 3:575-595.

Cherry KM, Lenze EJ, Lang CE (2014), Combining d-cycloserine with motor training does not result in improved general motor learning in neurologically intact people or in people with stroke. J Neurophysiol 111:2516-2524.

Chua R, Pollock BJ, Elliot D, Swanson LR, Carnahan H (1995), The influence of age on manual asymmetries in movement preparation and execution. Dev Neuropsychol 11:129-137.

Cigolle CT, Ofstedal MB, Tian Z, Blaum CS (2009), Comparing models of frailty: the Health and Retirement Study. J Am Geriatr Soc 57:830-839.

Coelho CJ, Przybyla A, Yadav V, Sainburg RL (2013), Hemispheric differences in the control of limb dynamics: a link between arm performance asymmetries and arm selection patterns. J Neurophysiol 109:825-838.

DeCarlo CA, Tuokko HA, Williams D, Dixon RA, MacDonald SW (2014), BioAge: Toward a multi-determined, mechanistic account of cognitive aging. Ageing Res Rev 18C:95-105. 
Derflinger S, Sorg C, Gaser C, Myers N, Arsic M, Kurz A, Zimmer C, Wohlschlager A, Muhlau M (2011), Grey-matter atrophy in Alzheimer's disease is asymmetric but not lateralized. J Alzheimers Dis 25:347-357.

Dolcos F, Rice HJ, Cabeza R (2002), Hemispheric asymmetry and aging: right hemisphere decline or asymmetry reduction. Neurosci Biobehav Rev 26:819-825.

Ebersbach G, Dimitrijevic MR, Poewe W (1995), Influence of concurrent tasks on gait: a dualtask approach. Percept Mot Skills 81:107-113.

Ferrand L, Jaric S (2006), Force coordination in static bimanual manipulation: effect of handedness. Motor Control 10:359-370.

Fitts PM (1954), The information capacity of the human motor system in controlling the amplitude of movement. J Exp Psychol 47(6):381-391.

Flowers K (1975), Handedness and controlled movement. Br J Psychol 66:39-52.

Forman DE, Berman AD, McCabe CH, Baim DS, Wei JY (1992), PTCA in the elderly: the "young-old" versus the "old-old". J Am Geriatr Soc 40:19-22.

Francis KL, Spirduso WW (2000), Age differences in the expression of manual asymmetry. Exp Aging Res 26: 169-180.

Franke K, Gaser C (2012), Longitudinal Changes in Individual BrainAGE in Healthy Aging, Mild Cognitive Impairment, and Alzheimer's Disease. GeroPsych 25:235-245.

Frayer DW, Fiore I, Lalueza-Fox C, Radovcic J, Bondioli L (2010), Right handed Neandertals: Vindija and beyond. J Anthropol Sci 88:113-127.

Freitas SM, Gera G, Scholz JP (2011), Timing variability of reach trajectories in left versus right hemisphere stroke. Brain Res 1419:19-33. 
Fried LP, Tangen CM, Walston J, Newman AB, Hirsch C, Gottdiener J, Seeman T, Tracy R, Kop WJ, Burke G, McBurnie MA (2001), Frailty in older adults: evidence for a phenotype. J Gerontol A Biol Sci Med Sci 56:M146-156.

Giovannetti T, Libon DJ, Buxbaum LJ, Schwartz MF (2002), Naturalistic action impairments in dementia. Neuropsychologia 40:1220-1232.

Goble DJ, Brown SH (2008), The biological and behavioral basis of upper limb asymmetries in sensorimotor performance. Neurosci Biobehav Rev 32(3):598-610.

Goble DJ, Mousigian MA, Brown SH (2012), Compromised encoding of proprioceptively determined joint angles in older adults: the role of working memory and attentional load. Exp Brain Res 216(1):35-40.

Goble DJ, Noble BC, Brown SH (2009), Proprioceptive target matching asymmetries in lefthanded individuals. Exp Brain Res 197(4):403-408.

Haaland KY, Harrington DL (1994), Limb-sequencing deficits after left but not right hemisphere damage. Brain Cogn 24:104-122.

Haaland KY, Harrington DL (1996), Hemispheric asymmetry of movement. Curr Opin Neurobiol 6:796-800.

Haaland KY, Harrington DL, Yeo R (1987), The effects of task complexity on motor performance in left and right CVA patients. Neuropsychologia 25:783-794.

Harrington DL, Haaland KY (1991), Hemispheric specialization for motor sequencing: abnormalities in levels of programming. Neuropsychologia 29:147-163.

Harrington DL, Haaland KY (1992), Motor sequencing with left hemisphere damage. Are some cognitive deficits specific to limb apraxia? Brain 115:857-874. 
Hartmann K, Goldenberg G, Daumuller M, Hermsdorfer J (2005), It takes the whole brain to make a cup of coffee: the neuropsychology of naturalistic actions involving technical devices. Neuropsychologia 43:625-637.

Hodges NJ, Lyons J, Cockell D, Reed A, Elliott D (1997), Hand, space and attentional asymmetries in goal-directed manual aiming. Cortex 33(2):251-269.

Jebsen RH, Taylor N, Trieschmann RB, Trotter MJ, Howard LA (1969), An objective and standardized test of hand function. Arch Phys Med Rehabil 50:311-319.

Jeste DV, Savla GN, Thompson WK, Vahia IV, Glorioso DK, Martin AS, Palmer BW, Rock D, Golshan S, Kraemer HC, Depp CA (2013), Association between older age and more successful aging: critical role of resilience and depression. Am J Psychiatry 170:188-196.

Judge J, Stirling J (2003), Fine motor skill performance in left- and right-handers: Evidence of an advantage for left-handers. Laterality 8:297-306.

Karadi K, Lucza T, Aschermann Z, Komoly S, Deli G, Bosnyak E, Acs P, Horvath R, Janszky J, Kovacs N (2015), Visuospatial impairment in Parkinson's disease: the role of laterality. Laterality 20:112-127.

Katz S, Downs TD, Cash HR, Grotz RC (1970), Progress in development of the index of ADL. Gerontologist 10:20-30.

Legon W, Dionne JK, Meehan SK, Staines WR (2010), Non-dominant hand movement facilitates the frontal N30 somatosensory evoked potential. BMC Neurosci 11:112.

Martin BJ, Adamo DE (2011), Contribution of sensory and motor components to motor control asymmetries: an analytical model approach. Conf Proc IEEE Eng Med Biol Soc 2011:4064-4067. 
Meguerditchian A, Vauclair J, Hopkins WD (2013), On the origins of human handedness and language: a comparative review of hand preferences for bimanual coordinated actions and gestural communication in nonhuman primates. Dev Psychobiol 55:637-650.

Michimata A, Kondo T, Suzukamo Y, Chiba M, Izumi S (2008), The manual function test: norms for 20- to 90-year-olds and effects of age, gender, and hand dominance on dexterity. Tohuku J Exp Med 214(3):257-267.

Mutha PK, Haaland KY, Sainburg RL (2012), The effects of brain lateralization on motor control and adaptation. J Mot Behav 44:455-469.

Naccarato M, Calautti C, Jones PS, Day DJ, Carpenter TA, Baron JC (2006), Does healthy aging affect the hemispheric activation balance during paced index-to-thumb opposition task? An fMRI study. Neuroimage 32:1250-1256.

Nasreddine ZS, Phillips NA, Bedirian V, Charbonneau S, Whitehead V, Collin I, Cummings JL, Chertkow H (2005), The Montreal Cognitive Assessment, MoCA: a brief screening tool for mild cognitive impairment. J Am Geriatr Soc 53:695-699.

Oldfield RC (1971), The assessment and analysis of handedness: the Edinburgh inventory. Neuropsychologia 9:97-113.

Paizis C, Skoura X, Personnier P, Papaxanthis C (2014), Motor Asymmetry Attenuation in Older Adults during Imagined Arm Movements. Front Aging Neurosci 6(49):1-9.

Postiglione A, Lassen NA, Holman BL (1993), Cerebral blood flow in patients with dementia of Alzheimer's type. Aging (Milano) 5:19-26.

Poston B, Enoka JA, Enoka RM (2008), Practice and endpoint accuracy with the left and right hands of old adults: the right-hemisphere aging model. Muscle Nerve 37(3):376-386. 
Przybyla A, Good DC, Sainburg RL (2012), Dynamic dominance varies with handedness: reduced interlimb asymmetries in left-handers. Exp Brain Res 216:419-431.

Raw RK, Wilkie RM, Culmer PR, Mon-Williams M (2012), Reduced motor asymmetry in older adults when manually tracing paths. Exp Brain Res 217:35-41.

Reppermund S, Brodaty H, Crawford JD, Kochan NA, Draper B, Slavin MJ, Trollor JN, Sachdev PS (2013), Impairment in instrumental activities of daily living with high cognitive demand is an early marker of mild cognitive impairment: the Sydney memory and ageing study. Psychol Med 43(11):2437-2445.

Reuter-Lorenz PA, Stanczak L, Miller AC (1999), Neural recruitment and cognitive aging: Two hemispheres are better than one, especially as you age. Psychol Sci 10:494-500.

Riederer P, Sian-Hulsmann J (2012), The significance of neuronal lateralisation in Parkinson's disease. J Neural Transm 119:953-962.

Roy EA, Elliott D (1986), Manual asymmetries in visually directed aiming. Can J Psychol 40:109-121.

Sainburg RL (2014), Convergent models of handedness and brain lateralization. Frontiers in psychology 5(1092):1-14.

Sainburg RL, Ghilardi MF, Poizner H, Ghez C (1995), Control of limb dynamics in normal subjects and patients without proprioception. J Neurophysiol 73:820-835.

Sainburg RL, Kalakanis D (2000), Differences in control of limb dynamics during dominant and nondominant arm reaching. J Neurophysiol 83:2661-2675.

Schaefer SY, Dibble LE, Duff K (2014), Efficacy and Feasibility of Functional Upper Extremity Task-Specific Training for Older Adults With and Without Cognitive Impairment. Neurorehabil Neural Repair. In press. 
Schaefer SY, Haaland KY, Sainburg RL (2007), Ipsilesional motor deficits following stroke reflect hemispheric specializations for movement control. Brain 130:2146-2158.

Schaefer SY, Haaland KY, Sainburg RL (2009a), Hemispheric specialization and functional impact of ipsilesional deficits in movement coordination and accuracy. Neuropsychologia 47:2953-2966.

Schaefer SY, Haaland KY, Sainburg RL (2009b), Dissociation of initial trajectory and final position errors during visuomotor adaptation following unilateral stroke. Brain Res 1298:78-91.

Schaefer SY, Lang CE (2012), Using dual tasks to test immediate transfer of training between naturalistic movements: A proof-of-principle study. J Mot Behav 44:313-327.

Schaefer SY, Mutha PK, Haaland KY, Sainburg RL (2012), Hemispheric specialization for movement control produces dissociable differences in online corrections after stroke. Cereb Cortex 22:1407-1419.

Schaefer SY, Patterson CB, Lang CE (2013), Transfer of training between distinct motor tasks after stroke: implications for task-specific approaches to upper-extremity neurorehabilitation. Neurorehabil Neural Repair 27:602-612.

Schmidt RT, Toews JV (1970), Grip strength as measured by the Jamar dynamometer. Arch Phys Med Rehabil 51:321-327.

Schwartz MF, Montgomery MW, Buxbaum LJ, Lee SS, Carew TG, Coslett HB, Ferraro M, Fitzpatrick-DeSalme E, Hart T, Mayer N (1998), Naturalistic action impairment in closed head injury. Neuropsychology 12:13-28. 
Soliveri P, Brown RG, Jahanshahi M, Marsden CD (1992), Effect of practice on performance of a skilled motor task in patients with Parkinson's disease. J Neurol Neurosurg Psychiatry $55: 454-460$.

Spirduso WW, Francis KL, MacRae PG (2007) Individual differences. In: Physical Dimensions of Aging, $2^{\text {nd }}$ edition, pp. 31-51. Champaign, IL: Human Kinetics.

Starkes J, Helsen W, Elliott D (2002), A ménage à trois: the eye, the hand and on-line processing. J Sports Sci 20(3):217-224.

Stewart JC, Gordon J, Winstein CJ (2014), Control of reach extent with the paretic and nonparetic arms after unilateral sensorimotor stroke: kinematic differences based on side of brain damage. Exp Brain Res 232:2407-2419.

Talelli P, Ewas A, Waddingham W, Rothwell JC, Ward NS (2008), Neural correlates of agerelated changes in cortical neurophysiology. Neuroimage 40:1772-1781.

Teixeira LA (2008), Categories of manual asymmetry and their variation with advancing age. Cortex 44(6)707-716.

Todor J, Doane T (1978), Handedness and hemispheric asymmetry in the control of movements. J Mot Behav 10:295-300.

Toga AW, Thompson PM (2003), Mapping brain asymmetry. Nat Rev Neurosci 4:37-48.

Tretriluxana J, Gordon J, Fisher BE, Winstein CJ (2009), Hemisphere specific impairments in reach-to-grasp control after stroke: effects of object size. Neurorehabil Neural Repair 23:679-691.

Uomini NT (2009), The prehistory of handedness: archaeological data and comparative ethology. J Hum Evol 57:411-419. 
Wang J, Przybyla A, Wuebbenhorst K, Haaland KY, Sainburg RL (2011), Aging reduces asymmetries in interlimb transfer of visuomotor adaptation. Exp Brain Res 210:283-290.

Wang J, Sainburg RL (2006), Interlimb transfer of visuomotor rotations depends on handedness. Exp Brain Res 175:223-230.

Ward NS (2006), Compensatory mechanisms in the aging motor system. Ageing Res Rev 5:239254.

Weissman DH, Banich MT (2000), The cerebral hemispheres cooperate to perform complex but not simple tasks. Neuropsychology 14:41-59.

Wilson RS, Schneider JA, Bienias JL, Evans DA, Bennett DA (2003), Parkinsonianlike signs and risk of incident Alzheimer disease in older persons. Arch Neurol 60(4):539-544.

Winstein CJ (1991), Knowledge of results and motor learning--implications for physical therapy. Phys Ther 71:140-149.

Winstein CJ, Pohl PS (1995), Effects of unilateral brain damage on the control of goal-directed hand movements. Exp Brain Res 105:163-174.

Zhao D, Hopkins WD, Li B (2012), Handedness in nature: first evidence on manual laterality on bimanual coordinated tube task in wild primates. Am J Phys Anthropol 148:36-44. 